\title{
1D photonic crystal sensor integrated in a microfluidic system
}

\author{
Nunes, Pedro; Mortensen, Asger; Kutter, Jörg Peter; Mogensen, Klaus Bo
}

Published in:

Conference proceedings, CLEO/QELS

Publication date:

2009

Document Version

Publisher's PDF, also known as Version of record

Link back to DTU Orbit

Citation (APA):

Nunes, P., Mortensen, A., Kutter, J. P., \& Mogensen, K. B. (2009). 1D photonic crystal sensor integrated in a microfluidic system. In Conference proceedings, CLEO/QELS IEEE.

\section{General rights}

Copyright and moral rights for the publications made accessible in the public portal are retained by the authors and/or other copyright owners and it is a condition of accessing publications that users recognise and abide by the legal requirements associated with these rights.

- Users may download and print one copy of any publication from the public portal for the purpose of private study or research.

- You may not further distribute the material or use it for any profit-making activity or commercial gain

- You may freely distribute the URL identifying the publication in the public portal

If you believe that this document breaches copyright please contact us providing details, and we will remove access to the work immediately and investigate your claim. 


\title{
1D PHOTONIC CRYSTAL SENSOR INTEGRATED IN A MICROFLUIDIC SYSTEM
}

\author{
P. S. Nunes, ${ }^{1, *}$ N. A. Mortensen, ${ }^{2}$ J. P. Kutter ${ }^{1}$ and K. B. Mogensen ${ }^{1}$ \\ ${ }^{1}$ Department of Micro- and Nanotechnology and ${ }^{2}$ Department of Photonics Engineering, Technical University of Denmark, DTU, Building 345 \\ east, 2800 Kgs. Lyngby, Denmark \\ *Corresponding author: pedro.nunes@nanotech.dtu.dk
}

\begin{abstract}
A refractive index sensor was designed as a 1D resonator incorporated in a microfluidic channel, where aqueous solutions were injected. A sensitivity of $480 \mathrm{~nm} / \mathrm{RIU}$ and a minimum difference of $\Delta \mathrm{n}=0.002$ were determined.

OCIS codes: (130.6010) Sensors; (130.3120) Integrated optics devices
\end{abstract}

A novel optofluidic system consisting of a one dimensional photonic crystal, integrated planar waveguides and electrically insulated fluidic channels is presented. The one dimensional photonic crystal consists of an array of silicon oxynitride pillars, which is used as a resonator for on-column label free refractive index detection. The resonator is part of a microfluidic channel designed for electrochromatography. This approach differs significantly from previous work, since the photonic crystal is not an array of holes in a Si membrane [1], but an array of pillars (Fig. 1). This fact enables the injection of fluid along the device plane, thus readily integrating the 1D photonic crystal within planar microfluidic channels [2].

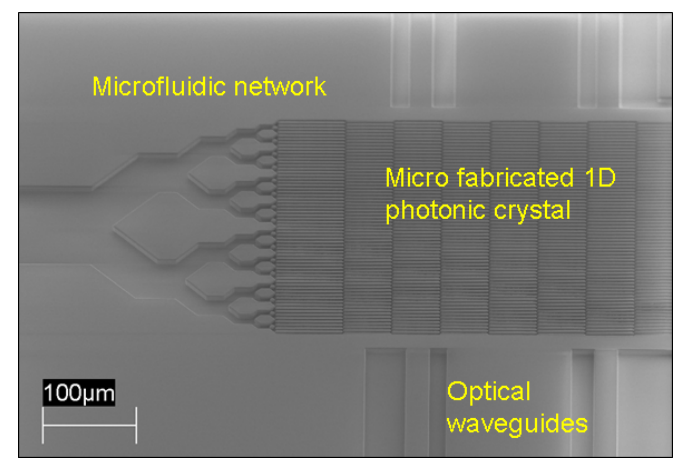

Figure 1 - SEM picture of the 1D photonic crystal, integrated waveguides and microfluidic channel, before anodic bonding of a glass lid. The microfluidic branching structure to the left ensures a constant flow resistance in the whole channel network.

Furthermore, it is fabricated in glass and not in silicon to support electroosmotic pumping of the liquid, thus significantly simplifying the external instrumentation, since pumps are avoided. This also makes it possible to use it as a detector in electrokinetic separation systems, thereby greatly extending the possible applications of photonic crystal sensors.

Infrared light $(\lambda=1.5-1.6 \mu \mathrm{m})$ was butt coupled in and out of the waveguides. The resonator with a thin layer of $200 \mathrm{~nm}$ a-Si on the pillars sidewall had a pitch of $5 \mu \mathrm{m}$. Mili-Q water and three different aqueous solutions of ethanol $(10 \%, 25 \%$ and $50 \%(\mathrm{v} / \mathrm{v}))$ with refractive indices ranging from $\mathrm{n}=1.3330$ to 1.3616 were pumped into the column/resonator ( 9 pillar array) and the transmission spectra were recorded. Increasing the fluid refractive index leaded to redshifts in the resonant wavelengths as can be seen in Fig. 2. Our device yielded a maximum sensitivity of $\Delta \lambda / \Delta \mathrm{n}=480 \mathrm{~nm} / \mathrm{RIU}$ and a Q-factor of 150 . 


\section{CFP4.pdf}

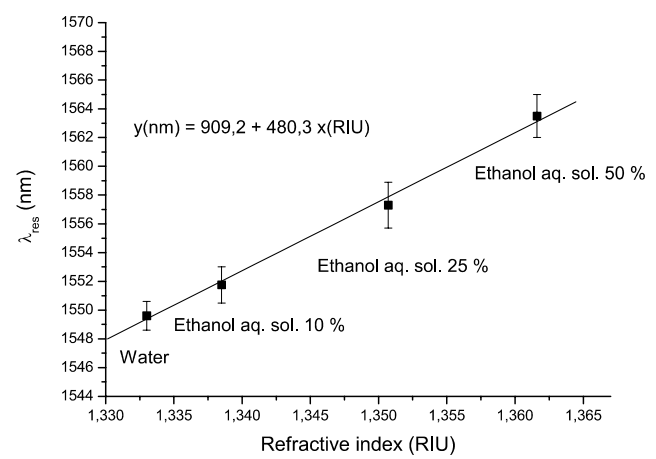

Figure 2 - Resonant wavelength plotted as a function of refractive index (n) for a 1D photonic crystal consisting of 9 pillars. Linear fit of the experimental data yields a sensitivity $\Delta \lambda / \Delta \mathrm{n} \approx 480 \mathrm{~nm} / \mathrm{RIU}$. The error bars refer to fluctuations on the resonant wavelength after successive injections of Mili-Q water and aqueous solutions of ethanol - $10 \%, 25 \%$ and $50 \%(\mathrm{v} / \mathrm{v})$.

Chip improvements were done by increasing the number of pillars, to 32 pillars, in the fluidic channel and by pumping the fluid of interest, $4 \mathrm{mM}$ Acetominophen in $5 \mathrm{mM}$ Tetra Borate buffer, electrokinetically (Fig 3). This was achieved, by applying a $1 \mathrm{kV}$ potential drop between fluidic reservoirs at the ends of the channel. This approach reduces considerably the mechanical noise and enabled a $1.4 \mathrm{~nm}$ shift to be recorded, whereas in the previous design only $2.2 \mathrm{~nm}$ shift could be measured. This enabled a minimum refractive index difference of 0.002 to be measured.

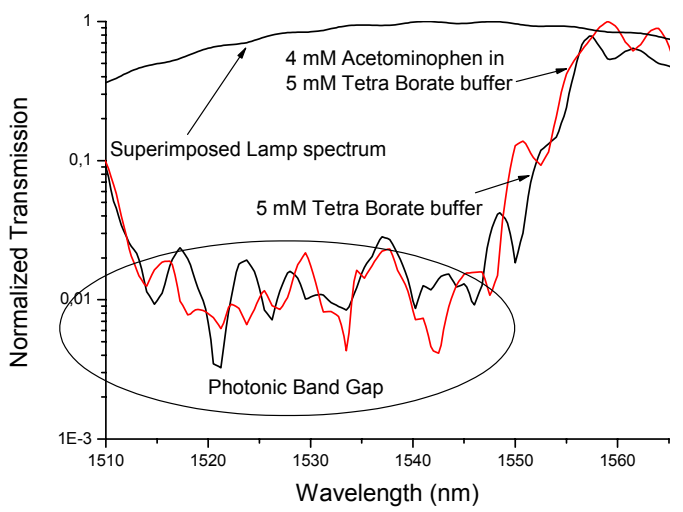

Figure 3 - Normalized transmission spectra of a 1D photonic crystal consisting of 32 pillars in the microfluidic channel. 4 mM Acetominophen in $5 \mathrm{mM}$ Tetra Borate buffer were injected electokinetically, enabling a minimum shift of $1.4 \mathrm{~nm}$ to be measured.

So far this is the highest sensitivity achieved in similar devices, with the added benefit of using the photonic structure for optical detection and in the future for chromatography purposes. Improvement of the Q-factor will be achieved by designing a resonator with a smaller pitch using E-beam lithography instead of conventional UV lithography.

Work supported by the Danish Research Council (FTP grant \#274-06-0193).

[1] E. Chow, A. Grot, L. W. Mirkarimi, M. Sigalas, and G. Girolami, "Ultracompact biochemical sensor built with two-dimensional photonic crystal microcavity," Opt. Lett. 29 (10), 1093-1095 (2004).

[2] P. S. Nunes, N. A. Mortensen, J. P. Kutter and K. B. Mogensen, "Photonic crystal resonator integrated in a microfluidic system," Opt. Lett. 33 (14), 1623-1625 (2008). 